\title{
Solusi Problem Dirichlet pada Daerah Persegi dengan Metode Pemisahan Variabel
}

\author{
M. Saleh $\mathbf{A F}^{*}$
}

\begin{abstract}
Abstrak
Dalam keadaan distribusi temperatur setimbang (tidak tergantung pada waktu) pada daearah persegi $a \times b$, pandang persamaan $\frac{\partial^{2} \mathrm{u}}{\partial \mathrm{x}^{2}}+\frac{\partial^{2} \mathrm{u}}{\partial \mathrm{y}^{2}}=0,0<x<a, 0<y<b$. Persamaan ini dikenal sebagai persamaan Laplace dalam dua variabel, yang diperoleh dari persamaan panas dengan membuat turunan terhadap waktu sama dengan nol. Persamaan Laplace dalam dua variabel beserta syarat-syarat batas yang diberikan, disebut masalah Dirichlet daerah Persegi. Dalam tulisan ini akan diuraikan pemecahan masalah yang didasarkan pada metode pemisahan variabel, dengan asumsi solusi berbentuk $u(x, y)=X(x) Y(y)$. Penyelesaian masalah Dirichlet di bagi ke dalam empat sub-bagian yang masing-masing memiliki satu syarat tak homogen. Solusi yang diperoleh merupakan jumlah dari ke empat solusi sub-bagian.
\end{abstract}

Kata Kunci: Masalah Dirichlet, persamaan Laplace, metode pemisahan variabel, nilai batas persegi.

\section{Pendahuluan}

Pandanglah konduksi panas dalam keadaan mantap pada daerah dua dimensi. Dalam hal ini temperatur diasumsikan setimbang (steady-state) dalam bidang persegi $(0 \leq x \leq a, 0 \leq y \leq$ $b$ ) dimana temperatur merupakan fungsi dari posisi (tidak tergantung pada waktu) pada batasbatas yang diberikan, seperti yang ditunjukkan pada Gambar 1 .

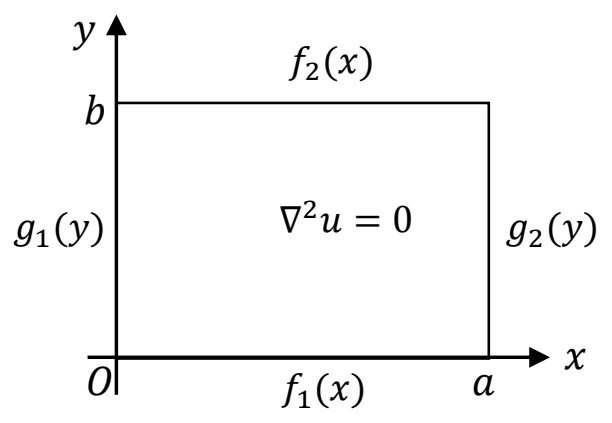

Gambar 1. Problem Dirichlet pada Daerah Persegi.

Dalam keadaan temperatur setimbang maka $u(x, y)$ memenuhi persamaan Laplace dengan syarat-syarat batas berikut:

* Jurusan Matematika, Fakultas Matematika dan Ilmu Pengetahuan Alam, Universitas Hasanuddin, Jl. Perintis Kemerdekaan Km.10, Tamalanrea, Makassar. 


$$
\nabla^{2} u=\frac{\partial^{2}}{\partial x^{2}} u(x, y)+\frac{\partial^{2}}{\partial y^{2}} u(x, y)=0, \forall 0 \leq \mathrm{x} \leq \mathrm{a}, 0 \leq \mathrm{y} \leq \mathrm{b},
$$

dengan syarat-syarat batas:

$$
\begin{aligned}
& u(x, 0)=f_{1}(x) ; u(x, b)=f_{2}(x) \\
& u(0, y)=g_{1}(y) ; u(a, y)=g_{2}(y)
\end{aligned}
$$

dimana $f_{1}, f_{2}$ adalah fungsi-fungsi dalam $x$ dan $g_{1}, g_{2}$ adalah fungsi-fungsi dalam $y$ yang diberikan.

Persamaan Laplace dua dimensi beserta syarat-syarat batas yang diberikan, di sebut problem Dirichlet pada daerah bidang persegi. Untuk menyelesaikan masalah ini, problem Dirichlet dibagi atas empat sub-bagian Dirichlet seperti pada Gambar 2, masing-masing memiliki satu syarat non-homogen. Solusi yang diperoleh merupakan jumlah dari empat sub-bagian, yang berbentuk:

$$
u(x, y)=u_{1}(x, y)+u_{2}(x, y)+u_{3}(x, y)+u_{4}(x, y)
$$

dimana setiap $u_{i}(x, y), i=1,2,3,4$ memenuhi persamaan Laplace dengan satu syarat batas tak homogen dan tiga syarat batas homogen. Metode penyelesaian untuk setiap $u_{i}(x, y)$ adalah sama, yaitu metode variabel terpisah dengan detail yang berbeda.

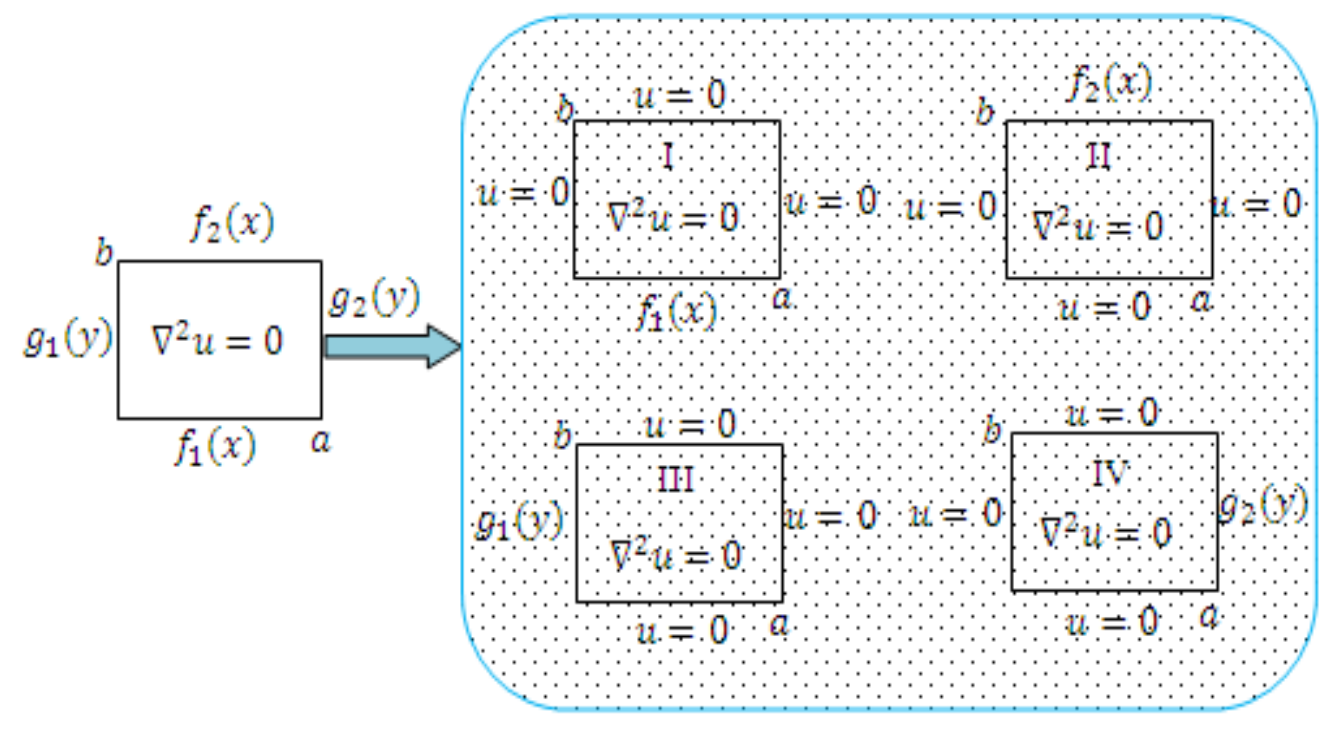

Gambar 2. Dekomposisi Problem Dirichlet ke Dalam Empat Sub-Bagian.

Bentuk persamaan dan syarat-syarat batas dari ke empat masalah ini adalah

(i) $\nabla^{2} u(x, y)=0$ atau $\frac{\partial^{2}}{d x^{2}} u(x, y)+\frac{\partial^{2}}{d y^{2}} u(x, y)=0$, dengan syarat batas: $u(x, 0)=f_{1}(x) ; u(x, b)=0 ; u(0, y)=0 ; u(a, y)=0$.

(ii) $\frac{\partial^{2}}{d x^{2}} u(x, y)+\frac{\partial^{2}}{d y^{2}} u(x, y)=0$, dengan syarat batas: $u(x, 0)=f_{2}(x) ; u(x, b)=u(0, y)=(a, y)=0$.

(iii) $\frac{\partial^{2}}{d x^{2}} u(x, y)+\frac{\partial^{2}}{d y^{2}}(x, y)=0$, 
dengan syarat batas: $u(0, y)=g_{1}(y) ;(x, 0)=u(x, b)=u(a, y)=0$.

$\frac{\partial^{2}}{d x^{2}} u(x, y)+\frac{\partial^{2}}{d y^{2}} u(x, y)=0$,

dengan syarat batas: $u(x, 0)=u(x, b)=u(0, y)=0 ;(a, y)=g_{2}(y)$.

\section{Pencarian Solusi dengan Metode Pemisahan Variabel}

yaitu

Pertama-tama, akan diselesaikan salah satu bagian, yaitu dimulai dengan sub bagian II,

$$
\frac{\partial^{2}}{d x^{2}} u(x, y)+\frac{\partial^{2}}{d y^{2}} u(x, y)=0,
$$

dengan satu syarat batas tak homogen dan tiga syarat batas homogeny, yaitu

$$
u(x, 0)=f_{2}(x) \text { dan } u(x, b)=u(0, y)=u(a, y)=0 .
$$

Pandang solusi dalam bentuk perkalian

$$
u(x, y)=X(x) Y(y)
$$

yang merupakan perkalian dua fungsi, masing-masing hanya tergantung pada satu variabel $x$ dan $y$. Persamaan (6) diturunkan secara parsial dua kali, diperoleh:

$$
\frac{\partial^{2}}{d x^{2}} u(x, y)=X^{\prime \prime}(x) Y(y) \text { dan } \frac{\partial^{2}}{d y^{2}} u(x, y)=X(x) Y^{\prime \prime}(y) \text {. }
$$

Subtitusi (7) ke (4), diperoleh $X^{\prime \prime}(x) Y(y)+X(x) Y^{\prime \prime}(y)=0$. Selanjutnya, kedua ruas dibagi dengan $X(x) Y(y)$ menjadi,

$$
\frac{X^{\prime \prime}}{X}+\frac{Y^{\prime \prime}}{Y}=0 \text { atau } \frac{Y^{\prime \prime}}{Y}=-\frac{X^{n}}{X}
$$

Ekspresi di ruas kiri dan ruas kanan masing-masing hanya tergantung dari satu variabel, maka kedua ekspresi tersebut haruslah sama dengan sebuah konstanta $k$, dan diperoleh dua persamaan differensial parsial orde dua:

$$
-\frac{X^{\prime \prime}}{X}=k \text { atau } X^{\prime \prime}+k X=0 \text { dan } \frac{Y^{\prime \prime}}{Y}=k \text { atau } Y^{\prime \prime}-k Y=0,
$$

yang memenuhi syarat-syarat batas dengan syarat-syarat batas (5). Tinjau persamaan berikut:

- $X^{\prime \prime}+k X=0$.

Jika $k \leq 0$, solusi trivial. Untuk $k>0$, katakanlah $k=\mu^{2}>0$, persamaan differensial tersebut berbentuk $X^{\prime \prime}+\mu^{2} X=0$ dan persamaan karakteristiknya $\lambda^{2}+\mu^{2}=0$, dengan akarakar karakteristik $\lambda=i \mu$ dan $\lambda=-i \mu$, sehingga solusi persamaan tersebut adalah

$$
\begin{gathered}
X(x)=A e^{i \mu x}+B e^{-i \mu x}=A(\cos \mu x+i \sin \mu x)+B(\cos \mu x-i \sin \mu x) \\
=(A+B) \cos \mu x+(i A-i B) \sin \mu x=c_{1} \cos \mu x+c_{2} \sin \mu x
\end{gathered}
$$

- $Y^{\prime \prime}-k Y=0$.

Jika $k=\mu^{2}>0$, persamaan karakteristiknya adalah $\lambda^{2}-\mu^{2}=0$, dengan akar-akar karakteristik $\lambda=\mu$ dan $\lambda=-\mu$, sehingga solusi persamaan tersebut adalah

$$
Y(y)=C_{1} e^{\mu y}+C_{2} e^{-\mu y}
$$




$$
\begin{aligned}
& =\left(\frac{A+B}{2}\right) e^{\mu y}+\left(\frac{A-B}{2}\right) e^{-\mu y}=\frac{A}{2}\left(e^{\mu y}+e^{-\mu y}\right)+\frac{B}{2}\left(e^{\mu y}-e^{-\mu y}\right) \\
& =A\left(\frac{e^{\mu y}+e^{-\mu y}}{2}\right)+B\left(\frac{e^{\mu y}-e^{-\mu y}}{2}\right)=A \cosh \mu y+B \sinh \mu y .
\end{aligned}
$$

Aplikasikan syarat-syarat batas (5) ke dalam solusi (6), yaitu:

- $u(x, 0)=X(x) Y(0)=0$.

Jelas bahwa jika $X(x)=0$, maka $u \equiv 0$, hal ini tidak menarik (karena masalah selesai sampai disini saja atau solusi menjadi trivial). Jadi pilih $X(x) \neq 0$, akibatnya $Y(0)=0$.

- $u(0, y)=X(0) Y(y)=0$.

Dengan alasan serupa, jika $Y(y)=0$, masalah selesai, jadi pilih $Y(y) \neq 0$, akibatnya $X(0)=0$.

- $u(a, y)=X(a) Y(y)=0$, dimana $Y(y) \neq 0$, akibatnya $X(a)=0$.

Jadi syarat-syarat batas untuk $X(x)$ dan $Y(y)$ adalah:

$$
X(0)=0, X(a)=0 \text { dan } Y(0)=0 .
$$

Aplikasikan syarat-syarat batas (12) ke dalam solusi (10) dan (11), yaitu

$$
X(x)=c_{1} \cos \mu x+c_{2} \sin \mu x, \text { memenuhi syarat-syarat batas: }
$$

- $X(0)=c_{1} \cos 0+c_{2} \sin 0=0, \Rightarrow c_{1}=0$.

- $X(a)=c_{1} \cos \mu a+c_{2} \sin \mu a=0$, karena $c_{1}=0 \Rightarrow c_{2} \sin \mu a=0$. Agar solusi tak trivial, haruslah $c_{2} \neq 0$. Akibatnya $\sin \mu a=0$, tetapi $\mu a \neq 0$, maka $\mu a=n \pi$ sehingga $\mu=u_{n}=$ $\frac{n \pi}{a}$. Jadi solusi untuk $X(x)$ adalah:

$$
X(x)=c_{2} \sin \frac{n \pi}{a} x
$$

Dengan cara serupa, $(y)=A \cosh \mu x+B \sinh \mu x$, memenuhi syarat batas (12).

- $Y(0)=A \cosh 0+B \sinh 0=0 \Rightarrow A=0$, sehingga solusi untuk $Y(y)$ adalah

$$
Y(y)=B \sinh \frac{n \pi}{a} y \text {. }
$$

Karena diinginkan solusi dalam bentuk perkalian maka berdasarkan persamaan (6), (13), dan (14), diperoleh:

$$
u(x, y)=f_{2}(x)=B_{n} \sin \frac{n \pi}{a} x \sinh \frac{n \pi}{a} y,
$$

yang merupakan fungsi dari $x$ saja, dengan konstanta $B_{n}=c_{2} B$. Berdasarkan prinsip superposisi, solusi umum dari sub II atau persamaan (4) yang memenuhi syarat-syarat batas (5), dapat dituliskan sebagai:

$$
f_{2}(x)=u_{2}(x, y)=\sum_{n=1}^{\infty} u_{2 n}(x, y)=\sum_{n=1}^{\infty} B_{n} \sin \frac{n \pi}{a} x \sinh \frac{n \pi}{a} y
$$

dengan

$$
B_{n}=\frac{2}{a \sinh \frac{n \pi b}{a}} \int_{0}^{a} f_{2}(x) \sin \frac{n \pi}{a} x d x
$$


yang disebut koefisien deret Fourier. Perhitungannya koefisien $B_{n}$ dilakukan sebagai berikut.

Kalikan $\sin \frac{m \pi}{a} x$, ( $m$ bilangan bulat positif) pada kedua ruas persamaan (16) kemudian integralkan dari 0 sampai $a$ :

$$
\begin{aligned}
\int_{0}^{a} f_{2}(x) \sin \frac{m \pi}{a} x d x & =\int_{0}^{a} \sum_{n=1}^{\infty} B_{n} \sin \frac{n \pi}{a} x \sinh \frac{n \pi}{a} y\left(\sin \frac{m \pi}{a} x\right) d x \\
& =\sum_{n=1}^{\infty} B_{n} \sinh \frac{n \pi}{a} y \int_{0}^{a} \sin \frac{n \pi}{a} x \sin \frac{m \pi}{a} x d x .
\end{aligned}
$$

Dengan mengaplikasikan rumus jumlah sudut trigonometri:

$$
\sin m x \sin n x=\frac{1}{2}[\cos (n-m) x-\cos (n+m) x]
$$

maka

$$
\begin{array}{r}
\int_{0}^{a} f_{2}(x) \sin \frac{m \pi}{a} x d x=\sum_{n=1}^{\infty} B_{n} \sinh \frac{n \pi}{a} y \int_{0}^{a} \frac{1}{2}\left[\cos \left(\frac{n \pi}{a}-\frac{m \pi}{a}\right) x-\cos \left(\frac{n \pi}{a}+\frac{m \pi}{a}\right) x\right] d x \\
=\sum_{n=1}^{\infty} \frac{1}{2} B_{n} \sinh \frac{n \pi}{a} y\left[\int_{0}^{a} \cos \left(\frac{n \pi}{a}-\frac{m \pi}{a}\right) x d x-\int_{0}^{a} \cos \left(\frac{n \pi}{a}+\frac{m \pi}{a}\right) x d x\right],
\end{array}
$$

dimana integral kedua di ruas kanan bernilai nol, sedangkan integral pertama ruas kanan juga bernilai nol ketika $n \neq m$, dan bernilai $a$ jika $n=m, \forall n=1,2, \cdots$.

Pilih $n=m$, integral pertama di ruas kanan menjadi

$$
\int_{0}^{a} \cos \left(\frac{n \pi}{a}-\frac{m \pi}{a}\right) x d x=\int_{0}^{a} \cos 0 d x=\int_{0}^{a} d x=a,
$$

dan diperoleh

$$
\int_{0}^{a} f_{2}(x) \sin \left(\frac{n \pi}{a} x\right) d x=(a)\left(\frac{1}{2} B_{n}\right) \sinh \left(\frac{n \pi}{a} y\right) .
$$

Untuk $y=b$, (syarat batas tak homogen $u(x, b)=f_{2}(x)$ ) diperoleh

$$
B_{n}=\frac{2}{a \sinh \frac{n \pi b}{a}} \int_{0}^{a} f_{2}(x) \sin \frac{n \pi}{a} x d x .
$$

\section{Perhitungan Solusi Masalah Dirichlet Sub-Bagian III}

Tinjau masalah untuk sub bagian III, yaitu

$$
\frac{\partial^{2}}{d x^{2}} u(x, y)+\frac{\partial^{2}}{d y^{2}} u(x, y)=0,
$$

dengan syarat batas:

$$
u(0, y)=g_{1}(y) \text { dan } u(x, 0)=u(x, b)=u(a, y)=0 .
$$

Bentuk solusi yang diinginkan adalah

$$
u(x, y)=X(x) Y(y) .
$$

Setelah didifferensialkan secara parsial dua kali dan disubtitusi pada problem (18), diperoleh dua persamaan diferensial parsial orde 2:

$$
\frac{X^{\prime \prime}}{X}=\mu^{2} \Leftrightarrow x^{\prime \prime}-\mu^{2} x=0
$$

dengan solusi $X(x)=A \cosh \mu x+B \sinh \mu x$. Dan 


$$
-\frac{Y^{\prime \prime}}{Y}=\mu^{2} \Leftrightarrow Y^{\prime \prime}+\mu^{2} Y=0,
$$

dengan solusi $Y(y)=c_{1} \cos \mu y+c_{2} \sin \mu y$. Kedua solusi terakhir ini memenuhi syarat-syarat batas:

(a) $u(x, 0)=X(x) Y(0)=0 \Rightarrow Y(0)=0$

(b) $u(x, b)=X(x) Y(b)=0 \Rightarrow Y(b)=0$

(c) $u(a, y)=X(a) Y(y)=0 \Longrightarrow X(a)=0$

Aplikasikan syarat-syarat batas ini pada solusi $X(x)$ dan $Y(y)$, yaitu

(a) $Y(0)=c_{1} \cos 0+c_{2} \sin 0 \Rightarrow c_{1}=0$

(b) $Y(b)=c_{1} \cos \mu b+c_{2} \sin \mu b=0$, karena $c_{1}=0$, maka $c_{2} \sin \mu b=0$. Agar solusi tak singulir, haruslah $c_{2} \neq 0$, akibatnya, $\sinh \mu b=0$, akan tetapi $\mu b \neq 0$, maka $\mu b=n \pi$ atau $\mu=\mu_{n}=\frac{n \pi}{b}$, sehingga solusi $Y(y)=c_{2} \sin \frac{n \pi}{b} y$.

(c) $X(a)=A \cosh \mu a+B \sinh \mu a=0$

sehingga solusi (20) menjadi $u(x, y)=\left(A \cosh \frac{n \pi}{b} x+B \sinh \frac{n \pi}{b} x\right) c_{2} \sin \mu y, c_{2} \neq 0$.

Dengan menerapkan rumus jumlah sudut fungsi hiperbolik, diperoleh

$$
u(x, y)=c_{2}\left(A^{*} \cosh \frac{n \pi}{b}(a-x)+B^{*} \sinh \frac{n \pi}{b}(a-x)\right) \sin \frac{n \pi}{b} y
$$

dengan $a$ bilangan tertentu, yang memenuhi syarat batas $u(a, y)=0$, yaitu

$$
\begin{aligned}
u(a, y)= & \left(A^{*} \cosh \frac{n \pi}{b}(a-a)+B^{*} \sinh \frac{n \pi}{b}(a-a)\right) \sin \frac{n \pi}{b} y=0 \\
& \left(A^{*} \cdot 1+B^{*} 0\right) \sin \frac{n \pi}{b} y=0 \Rightarrow A^{*}=0 .
\end{aligned}
$$

Jadi solusi persamaan (18) yang memenuhi syarat-syarat batas (19) adalah

$$
g_{1}(y)=u_{3}(x, y)=C_{n} \sinh \frac{n \pi}{b}(a-x) \sin \frac{n \pi}{b} y
$$

atau berdasar prinsip superposisi menjadi:

$$
g_{1}(y)=u_{3}(x, y)=\sum_{n=1}^{\infty} C_{n} \sinh \frac{n \pi}{b}(a-x) \sin \frac{n \pi}{b} y
$$

dengan

$$
C_{n}=\frac{2}{b \sinh \frac{n \pi a}{b}} \int_{0}^{b} g_{1}(y) \sin \frac{n \pi}{b} y d y
$$

Penurunan rumus untuk sub-bagian (i) dan (iv) diperoleh dengan cara serupa, terutama untuk sub bagian (iv), hanya mempertukarkan $a$ dan $b$ serta $x$ dan $y$, sehingga diperoleh solusi (iv) dan (i) masing-masing adalah:

$$
u_{4}(x, y)=g_{2}(y)=\sum_{n=1}^{\infty} D_{n} \sinh \frac{n \pi}{b} x \sin \frac{n \pi}{b} y,
$$


dengan

$$
\begin{aligned}
& D_{n}=\frac{2}{b \sinh \frac{n \pi a}{b}} \int_{0}^{b} g_{2}(y) \sin \frac{n \pi}{b} y d y, \\
& u_{1}(x, y)=f_{1}(x)=\sum_{n=1}^{\infty} A_{n} \sin \frac{n \pi}{a} x \sinh \frac{n \pi}{a}(b-y),
\end{aligned}
$$

dengan

$$
A_{n}=\frac{2}{a \sinh \frac{n \pi b}{a}} \int_{0}^{a} f_{1}(x) \sin \frac{n \pi}{a} x d x .
$$

Jadi solusi komplit dari masalah Dirichlet pada Gambar 1 adalah jumlah dari solusi sub-sub bagian yaitu:

$$
\begin{aligned}
& u(x, y)=u_{1}(x, y)+u_{2}(x, y)+u_{3}(x, y)+u_{4}(x, y) \\
& =\sum_{n=1}^{\infty} A_{n} \sin \frac{n \pi}{a} x \sinh \frac{n \pi}{a}(b-y)+\sum_{n=1}^{\infty} B_{n} \sin \frac{n \pi}{a} x \sinh \frac{n \pi}{a} y \\
& \quad+\sum_{n=1}^{\infty} C_{n} \sinh \frac{n \pi}{b}(a-x) \sin \frac{n \pi}{b} y+\sum_{n=1}^{\infty} D_{n} \sinh \frac{n \pi}{b} x \sin \frac{n \pi}{b} y
\end{aligned}
$$

dengan koefisin-koefisien

$$
\begin{aligned}
& A_{n}=\frac{2}{a \sinh \frac{n \pi b}{a}} \int_{0}^{a} f_{1}(x) \sin \frac{n \pi}{a} x d x ; B_{n}=\frac{2}{a \sinh \frac{n \pi b}{a}} \int_{0}^{a} f_{2}(x) \sin \frac{n \pi}{a} x d x \\
& C_{n}=\frac{2}{b \sinh \frac{n \pi a}{b}} \int_{0}^{b} g_{1}(y) \sin \frac{n \pi}{b} y d y ; D_{n}=\frac{2}{b \sinh \frac{n \pi a}{b}} \int_{0}^{b} g_{2}(y) \sin \frac{n \pi}{b} y d y
\end{aligned}
$$

\section{Daftar Pustaka}

Kreyszig, E., 1983. Advanced Enggineering Mathematics. John Wiley \& Sons Inc., New York.

Asmar, N., 2004. Partial Differential Equation with Fourier Series. Pearson-Prentice Hall, USA.

Kartono, 2001. Maple untuk Persamaan Differensial. J \& J Learning, Yogyakarta. 